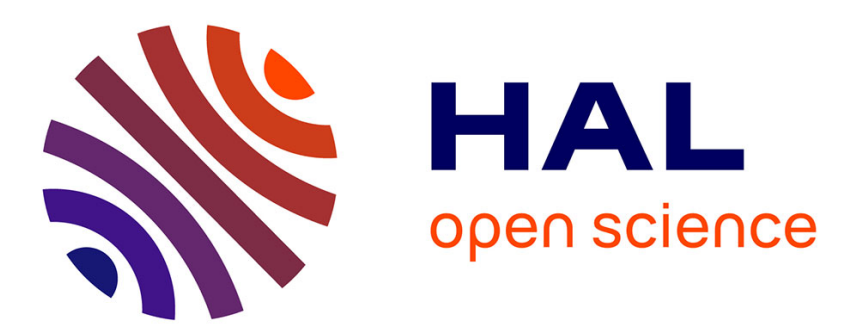

\title{
International dimension to increase Lifelong Learning possibilities in Europe
}

Jean-Marc Thiriet, Hamed Yahoui, Hélène Fremont

\section{To cite this version:}

Jean-Marc Thiriet, Hamed Yahoui, Hélène Fremont. International dimension to increase Lifelong Learning possibilities in Europe. ITHET 2012 - International Conference on Information Technology Based Higher Education and Training, Jun 2012, Istanbul, Turkey. pp.PS11. hal-00719906

\section{HAL Id: hal-00719906 https://hal.science/hal-00719906}

Submitted on 22 Jul 2012

HAL is a multi-disciplinary open access archive for the deposit and dissemination of scientific research documents, whether they are published or not. The documents may come from teaching and research institutions in France or abroad, or from public or private research centers.
L'archive ouverte pluridisciplinaire HAL, est destinée au dépôt et à la diffusion de documents scientifiques de niveau recherche, publiés ou non, émanant des établissements d'enseignement et de recherche français ou étrangers, des laboratoires publics ou privés. 


\section{International dimension to increase Lifelong Learning possibilities in Europe}

\author{
Jean-Marc Thiriet, Prof., EAEEIE member, IEEE \\ member \\ GIPSA-Lab, Université Joseph Fourier \\ F-38402 Saint-Martin d'Hères, France \\ jean-marc.thiriet@ujf-grenoble.fr
}

\author{
Hamed Yahoui, Dr, EAEEIE member \\ Université Claude Bernard Lyon 1, France \\ Hélène Frémont, Dr, EAEEIE member \\ Université Bordeaux 1, France
}

\begin{abstract}
Thanks to the European policy, mobility of students has been encouraged via ERASMUS, allowing universities to recognise, within their programmes, semesters or complete academic years spent abroad. Within the frame of global European projects, such as the ERASMUS Thematic Networks [www.elleiec.eu], Tuning approach was proposed as a way to facilitate both exchange of students during their studies and mobility of workers during their professional life. The philosophy behind that is not to focus too much about the actual courses followed by a student (which is extremely tricky when a student is sent abroad) but more on what he gets as a whole concerning knowledge, skills and competences, taking also account of soft or generic skills like internationalization, multiculturalism, teamgroup work, foreign language... Another interesting aspect is the use of tools like RPL (Recognition of Prior Learning) which is very useful, when we want to give a worker the possibility to pass a diploma, based on the partial or total recognition of his professional knowledge, skill and competences. The present paper develops the work achieved within the ELLEIEC project, relative to International Modules (IM) and International Curricula Networks (ICN), concepts proposed in the project and experimented practically, to facilitate the mobility of students and of citizens/workers.
\end{abstract}

Keywords-component; Lifelong Learning, recognition, mobility of students, harmonization, Recognition of Prior Learning (RPL), accreditation.

\section{INTRODUCTION}

One of the aims of the ELLEIEC (Enhancing Lifelong Learning in Electrical and Information Engineering, http://greenelleiec.eu/) project (proposed by the EAEEIE, European Association for Education in Electrical and Information Engineering, www.eaeeie.org), Thematic Network launched in 2008 for a three and a half year-duration, was to propose a synthesis about how to ensure mobility of students during their studies and also of citizens (workers) during their professional lives, in a LLL (Life-Long Learning) approach.

Questionnaires have been designed and filled, all around Europe, in order to have an overview of the use of Lifelong Learning approaches (such as RPL for instance) in the various countries. The working group of the ELLEIEC project has also proposed "best practices" for the use of RPL approaches throughout Europe.
Some benchmarks are proposed, in order to show various tools that can be used (ERASMUS, ERASMUS Mundus, Atlantis, Curriculum Development programmes, bilateral agreements) which are more or less "light", as far as the implementation is concerned, and may be used quite easily to implement dual degree or double diploma programmes.

The last aspect proposed in the project is the concept of ICN (International Curricula Network) which deals with group of experts, being able to work together on an international basis, and defining IM (International Modules) which are basically modules which are proposed in at least two accredited programmes, in two various countries. These International Modules can be provided for Lifelong Learning.

\section{SOME CONSIDERATIONS ABOUT RPL, ACCREDITATION AND LLL}

RPL (Recognition of Prior Learning) is an interesting approach for LLL since it allows to "open” the mobility of students and the mobility of citizens. This approach consists not only in measuring learning outcomes and knowledge, which is classically applied, but to measure for a "student" her/his actual knowledge, skill and competence (KSC). This approach was formalised in particular by the Tuning project [1]. The interest of such an approach is manifold:

- For classical students leaving their home university $(\mathrm{HU})$ to spend a semester in a partner university (PU), the KSC approach helps in building a specific programme for the student, using the available PU courses, and not too strictly follow the programme of the HU.

- For classical students coming back from their mobility, it is easier to "recognise" from the HU the semester spent abroad, considering once again the whole KSC, preferably to specific exact comparable courses.

- For every citizens, and in phase with the White book of the European Union on "mobility of citizens/workers" [2], the KSC approach, used for instance in the European Qualification Framework ([3], [4]) helps in considering the complete professional experience of citizens/workers at the time to consider either to 
actually deliver them a diploma or to give them the possibility to enter into a programme, with some partial recognition (using continuous education for instance).

Accreditation is an important aspect at this stage. To allow the mobility of students or citizens through an accredited programme, it means that the accreditation allows this:

- In some countries or types of institutions, the accreditation board requires that the programme is completely defined and fixed, for the complete duration of the accreditation: in this case it is difficult to send students abroad or accept a KSC recognition, because in this case, the programme does not fit exactly. This is a "strict" way to see accreditation, with no margin for mobility.

- In some countries, after discussion with colleagues within European projects, it seems impossible to envisage a complete KSC (RPL) approach, because there are some risks that people "buy" their diploma. In this case, the accreditation process must guarantee the quality of the approach (for instance RPL).

- In some countries or Higher Education Institutions, the accredited programmes are organised in a more "open" manner, by using "minor" (combination of a major field of study and a minor field of study, this "minor" can be obtained and validated through a mobility) or by using for instance "international minor term" (in this case, the university encourages explicitly students to spend some times abroad and their experience is validated and recognised). Some US universities are developing mobility through this approach and in France, the "Commission des Titres de l'Ingénieur" (CTI) encourages HEIs to have a high percentage of students going for one semester at least abroad during their studies.

Various mechanisms can be envisaged for Lifelong Learning, once we consider giving the possibility for citizens to learn new things and gain credits, to validate competences, all their life long.

Three points should be taken into account:

- The actual situation of the learner, a) normal registered student, b) student with a specific contract, c) worker from a company.

- $\quad$ The way the courses are organised, a) classical class, b) evening and week-end courses, c) intensive courses, d) programmes specifically organised for people working in companies (suite of intensive weeks) e) synchronous e-programmes (programmes with tutor, with milestones), f) asynchronous e-programmes (with or without tutors), g) no organised courses (APEL).

- The type of contract between the learner, the company (if any) and the Higher Education Institution.

\section{QUESTIONNAIRE ABOUT RPL}

Two questionnaires have been elaborated, one for the "bachelor and master" (BM) levels and one for the Doctoral level $(\mathrm{PhD})$ [5]. We focus here on the questionnaire for $\mathrm{BM}$ which is composed of four sets of questions.

The first set of questions discusses about credits:

- Do you know what ECTS is? Are you using ECTS in your own university? Who is in charge to design the learning agreement related to ECTS?

- Do you know what a Diploma Supplement (DS) is? Are you using the DS in your own university? Who is in charge to design the DS?

- Do you know what ECVET is? Are you using ECVET in your own university? Who is in charge to record a prior learning with ECVET?

- What kind of grant your university provide for an ongoing student: European one, National one, Regional one, self University funding?

- What kind of grant your university provide for an incoming student: European one, National one, Regional one, self University funding?

The second set of questions is relative to the national policy in LLL:

- Do you have any official governmental/ministerial policy on LLL?

- In your country, does the LLL process include one of the following: Accreditation of Prior Learning (APL) or Accreditation of Prior Experiential Learning (APEL)

A third set of questions concerns the programmes which are available through LLL

- Types of programmes/courses for which officially recognized LLL credits are awarded in your country (recognition means "It gives credits (ECTS) to go to the next level or to obtain the final diploma"): Regular University Programs, Bachelor, Master, Single courses/modules, Vocational training.

The fourth set of questions is composed of the two following questions:

- Admission possibilities for students with foreign based APL/APEL?

- Where compulsory internship is part of a programme, is it possible to get credits for previous practical work/experience?

The results of the questionnaires are available in the book published by the project [6].

\section{IMPLEMENTATION OF SOME BENCHMARKS}

It was decided, at the origin of the project, to propose some methodologies or tools, making possible to enhance mobility 
and cross-recognition. Another idea is the fact that the ERASMUS exchange programme, very well known at the European level, is based on bilateral agreements, but we think we can work also with a multilateral approach. We have introduced [7] in the ELLEIEC project approach the concept of International Curricula Network (ICN) (see Fig. 1) [7] whose purpose is to define a "soft" or "light" dynamic frame for the setting of multilateral collaborations. The use of existing programmes of the European Union can be a very good support (we give as examples Curriculum Development Programmes, Intensive Programmes, ERASMUS, Atlantis...). Crossrecognition is a basic condition, which can under certain assumptions lead to a double-diploma.

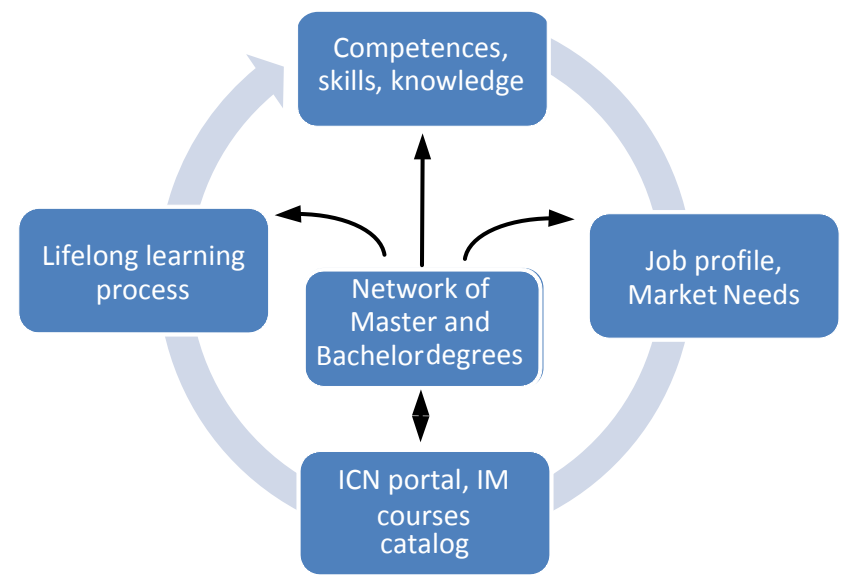

Figure 1. Scheme presenting the concepts and International Modules and International Curricula Networks

Within the ELLEIEC project, International modules (IM) have been defined as modules which are recognised and validated in at least two accredited programmes in two different countries.

The following ICN have been defined in the project:

- ICN.1 Master in Renewable and embedded energy,

- ICN.2 Master in Vision,

- ICN.3 Bachelor in Networking and Communication,

- $\quad$ ICN.4 Bachelor in Electrical Engineering (Automatic control),

- ICN.5 Master in Electronics and Telecom.

ICN 2, 3, 4 and 5 are actually running existing bachelor (3 and 4 ) or master courses (2 and 5). ICN 1 is setting a new master programme.

We can mention the fact that ICN 2 (Master in vision) is using ERASMUS-Mundus + ERASMUS exchanges and bilateral agreements [7]. The following sub-sections will describe ICN 3 (an existing bachelor programme) and ICN 1 (a new master to be proposed).

\section{A. An existing Bachelor in Wireless networks and security}

The Professional Bachelor's Degree "Networks and Telecommunications" specialising in "wireless networks and security" started in Grenoble in September 2005 (Frenchspeaking programme). In the French system, this programme concerns the last year of a bachelor's degree level (3 years and 180 ECTS) which means the 5th and 6th semester of the bachelor's degree programme. In order to develop international exchanges, especially with European countries where French is not so widespread in the technological fields, we decided to set up an international group, reduced in numbers, 14 students, with the same modules taught in English [8]. This programme began in September 2007, and concerns only, as mentioned before, the 5th and 6th semesters.

a. International Modules based on the cross-recognition thanks to mobility of students

The ICN which exists around this programme is composed of several universities among which two from the USA1. This first set of partners is concerned by student exchange, which means that students from these institutions attended the international programme in Grenoble. These exchanges were organised within the frame of ERASMUS exchanges for the European partners, within a specific bilateral agreement with CEFET-Minais Gerais, and within the Atlantis Programme (project DESIRE2: Dependable Systems International Research and Educational Experience, http://www.desire. agh.edu.pl) for the US partners. All the concerned students validated at least some of the courses passed in Grenoble for their home programme (so the concerned modules are International Modules) and most of them validated at the same time the French diploma, which gave them the opportunity to get a double-diploma.

Most students follow the complete year, some of them only one semester. It means that Grenoble's modules are recognised by approximately all partner universities (sometimes only parts of the Grenoble's modules are recognised by the partner university, depending also on the content of the programme of the partner university). In the case of one Finnish student, he came at Grenoble for the fifth semester only, and the sixth semester was composed of two courses: "Databases" and "Law of internet" followed by the training period. In order to be able to get the French diploma, we did a "reverse-ERASMUS", which means that we validated the Database module and the internship he passed in Finland. Concerning "Law for internet", we asked him to write a memoir. The US students came for one semester only, with a selection of "à la carte" courses, so they didn't get the French diploma.

b. International Modules based on the cross-recognition thanks to mobility of teachers

1 Universidade de Vigo (ES), Technical university of Kosice (SK), AGH University of science and Technology (PL), Helsinki Metropolia UAS (FI), Universidad Politécnica de Valencia (ES), Haute-Ecole de la Province de Liège (BE), Silesian University of Technology (PL), Cracow University of Technology (PL), Technical University of Crete (GR), CEFETMinais Gerais, Belo Horizonte (BR), Embry-Riddle Aeronautical University, Daytona Beach, Florida (USA), University of Central Florida (USA). 
Another interesting aspect for the potential multilateral aspect of International modules is the use of staff-mobility which is actually used with 7 European partners ${ }^{2}$. These colleagues come to Grenoble to provide some courses to our international students. It means that the model we use in this case is: a student from a country A institution A (example: a student from Krakow) receives in Grenoble a course by a teacher coming from a country B institution B (example: a teacher from Vigo) which means that 3 countries/institutions are considered, the third being Grenoble (example: Krakow, Vigo and Grenoble).

c. International Modules based on the cross-recognition thanks to common courses at the same place

For the Academic projet of students, Grenoble have been since September 2010 part of an Intensive Programme called DOSSEE (Developing Open Source System Expertise in Europe) composed of 7 European partners ${ }^{3}$. The students (10 from each university for each of the 7 universities) had first to prepare the definition of a project, this was prepared at home universities from October to January and then, all these students spent altogether 2 weeks in March 2011 in Alcala (Spain) in order to develop their IT projects in an international and multicultural environment, because the teams in Alcala were composed of students coming from the various partner universities. Academic project is so evaluated in an international basis, with students coming from 7 institutions, by an international committee of teachers. This is considered as an international module (5 ECTS) part of the actual curriculum of the students in the 7 universities. This is actually a join module with the same evaluation done by the same set of international teachers for the students of the seven universities.

d. International Modules based on the cross-recognition thanks to common courses at one place, using e-distant possibilities

This has not been implemented yet exactly in this international programme (and by this ICN) but some developments are on the way, within the frame of other programmes such as the Curriculum Development Programme ESPANT (European Study Programme for Advanced Networking Technologies, http://www.advancednetworking.eu/) [9] composed by 5 partners ${ }^{4}$. Courses have been developed, to be used on a distant

2 Universidade de Vigo (ES), Technical university of Kosice (SK), Helsinki Metropolia UAS (FI), Haute-Ecole de la Province de Liège (BE), Faculty of Law, Aristotle University (GR), Università degli Studi di Salerno (IT), Technical University of Brno (CZ)

3 Helsinki Metropolia University of Applied Sciences (FI), Universidad de Alcala (ES), Transport and Telecommunication Institute (Riga, LV), FH Joanneum (AT), Technical university of Kosice (SK), Danish Technical University, Copenhagen (DK).

4 Katholieke Hogeschool Sint-Lieven (BE), Universitat de Girona (ES), Instituto Superior de Engenharia - Instituto Politécnico do Porto (PT), Helsinki Metropolia University of basis. These courses can become potentially International Modules, when they will be actually used and recognised by at least two partner institutions, which is not the case yet.

\section{B. A new master programme in Green Energy}

In recent years, there has been an increased awareness in the European public and political arena of the need for reducing the dependence on fossil fuel by aiming towards a $100 \%$ green energy agenda by 2050 . Indeed, the Directive on renewable energy sets ambitious targets for all Member States, such that the EU will reach a $20 \%$ share of energy from renewable sources by 2020 and a 10\% share of renewable energy specifically in the transport sector. This agenda is not only governed by the fact that fossil energy is getting scared and by the volatile price of oil but also by the lifestyle of its population that are increasingly reliant on new technologies and comfort that are energy-intensive. It is therefore clear that in the years to come there will be an ever growing demand in electricity and an imperative need for saving and storing energy.

One of the benefits of moving towards a green energy future is the large number of jobs that are naturally created in the renewable energy and related sector. It is estimated that more than 2.7 million jobs will be created by 2020 if Europe adopts a full renewable energy agenda. HEI have to respond to this objective by proposing new diploma related to green jobs.

Currently, several ELLEIEC partners are responsible for undergraduate and postgraduate degrees in renewable energies and sustainable systems. They have decided to start the design of an ICN dedicated to sustainable electrical systems and renewable energy field. Involvement in the project will consist in implementing the result of the project in their own country applied to their corresponding degrees. They have a long experience and they are currently fully active in delivering these types of courses. Some of them will bring their own specificity due to their local environment, such as the Icelandic partner regarding geothermal energy.

\section{CONCEPTS OF INTERNATIONAL MODUlES (IM) AND INTERNATIONAL CURRICULA NETWORKS (ICN)}

These experiments show some possibilities to implement multilateral partnership, using both combinations of bilateral actions (ERASMUS, bilateral agreements...) and existing multilateral programmes (IP, CD...). For the first ICN, the set of partners is 23, or 19 if we consider actual running International Modules. The modules are recognised or crossrecognised by at least 2 institutions, and so they can be displayed in the library of international modules provided for Lifelong Learning by the ELLEIEC project. We can mention the fact that since the benchmark programme proposed (Professional Bachelor in Wireless Networks and Telecommunications) is composed of International Modules and also because this is the last year of a programme leading to a diploma (3rd year of an 180 ECTS-bachelor programme), it

Applied Sciences (FI), University of Ljubljana, Faculty of Education (SI). 
is possible to allow the students to get two diplomas, one from their home university and one from Grenoble.

For the second ICN the work is in the starting phase and will follow the objectives listed below:

- to define correctly the competences, skills and knowledge behind green jobs in the spirit of 'new skill for a new job',

- to define a useful searching database of learning outcomes about renewable and efficient energy sector

Taking advantage of the experience of the ICN in Wireless Network and Security, the new green consortium will apply for a part the methodology developed in the ILERT project [10] to design his own ICN.

\section{CONCLUSIONS}

The discussions in the working group of ELLEIEC-partners and the analysis of the questionnaire have given us the picture of the present situation in Europe. There are different practices concerning recognition of diploma and recognition of obtained competencies in different countries and even in different universities. The work done by the working group of ELLEIEC-partners showed many differences in how APL and APEL are used in validation of the programme.

The implementation on some benchmarks, mainly a bachelor programme in Networking and Telecommunications and a master programme on Green Energy are proposed.

\section{ACKNOWLEDGMENT}

The authors wish to thank the European Commission for the grant in the Life long Learning Programme, the Executive Agency for its help and all the partners of the project for their contribution.

Project Number: ELLEIEC 142814-LLP-1-2008-FRERASMUS-ENW - Instrument type: ERASMUS NETWORK

as well as the grants obtained by various consortia for:

- ESPANT (European Study Programme for Advanced Networking Technologies), Curriculum Development Programme

- « Intensive programme » DOSSEE, « Developing Open Source System Expertise in Europe ».
- ILERT Toward International Learning Environment for Real-Time Safety-Critical Control Systems (thanks also to the US Department of Education for this project).

- DESIRE2 Dependable Systems International Research and Educational Experience, http://www.desire.agh.edu.pl (thanks also to the US Department of Education for this project).

Not all the persons are authors of this paper, but the authors wish to strongly thank all the partners of the above-mentioned projects, in particular colleagues from exchange programmes, partners from ELLEIEC involved in the task and the experiments, partners of ESPANT, DOSSEE, ILERT, DESIRE2 projects which are used as examples.

\section{REFERENCES}

[1] Tuning, Tuning Educational Structure in Europe. Final Report Pilot Project - Tuning project, Ed. J. Gonzalez and R. Wagenaar, Deusto and Groningen, 2005.

[2] White book knowledge, European Commission

[3] Commission of the European Communities, The European Qualifications Framework (EQF), 2008.

[4] M.H.W. Hoffmann, J. Grünberg, M. Hampe, H.U. Heiß, G. Müller, H. Schmitt - A Sectoral Qualification Framework for Engineers and Computer Scientists - EAEEIE’09 Conference, Valencia.

[5] O. Bonnaud \& al. - PhD in Electrical and Information Engineering in Europe: towards a harmonization including LiveLong LearningITHET'12, Istanbul.

[6] Under the coordination of $\mathrm{H}$. Yahoui - Lifelong learning in ELECTRICAL and INFORMATION ENGINEERING in Europe 2008-2012.

[7] J. M. Thiriet, F. Meriaudeau, J. C. Burguillo, H. Fremont, H. Yahoui, P. de Fooz - Toward an International Curricula Network for exchanges and LifeLong Learning - Electronics and Electrical Engineering, No. 10 (106), December 2010, ISSN 1392-1215 (print), pp. 147-150, ISSN 2029-5731 (online), 1392-1215 (paper).

[8] Jean-Marc Thiriet, Denis Lubineau, Philippe Benech, Emil Novakov, Anna Derioz, Jean-Michel Terriez - A New International "Professional" Bachelor's Degree in Wireless Networks and Security - 19th annual EAEEIE Conference, Tallinn, Estonia, 30 June - 2 July 2008, pp.88-93, 978-1-4244-2009-4.

[9] J. Rugelj, JL Marzo, S. Knockaert, R. V. Steenberghe, L. Schoofs, J. Salonen, K. Bjorn, C. Vaz de Carvalho - "Competence based joint study program on advanced networking technologies for blended learning” ITHET 2010.

[10] A. Kornecki, T. Hilburn, W. Grega, M. Sveda, and J.-M. Thiriet, "ILERT, international learning environment for real-time softwareintensive control systems,” Journal of Automation, Mobile Robotics and Intelligent Systems (JAMRIS), vol. 3, no. 3, pp. 66-71, 2009. 